\title{
Drinking Water and CKD of Unknown Etiology in Sri Lanka: A Community Perspective
}

\author{
M.W. Amarasiri de Silva \\ Department of Behavioral and Community Health Sciences, University of Pittsburgh and Emeritus Professor, \\ University of Peradeniya, Sri Lanka, Pittsburgh, PA, USA
}

\section{Keywords \\ CKD of unknown etiology · Drinking water - Reverse osmosis water · Disease progression · Community perspective $\cdot$ Sri Lanka $\cdot$ Anthropology}

\begin{abstract}
People's belief that polluted drinking water is the principal medium through which environmental toxins are absorbed into the bodies of CKD of unknown etiology (CKDu) patients in the CKDu-endemic areas in Sri Lanka has been the subject of extensive epidemiological and medical research. This study examines (a) the people's perception and experience that polluted drinking water is the cause of CKDu, (b) how the government responded to people's demands for potable water, and (c) the impact of the use of alternative drinking water sources on the health of CKDu patients and their families, and on the progression of the disease in CKDu patients. Data were collected in 2013 and 2019 in Anuradhapura and Polonnaruwa districts in North Central Province of Sri Lanka. People's agitation, activism, and lobbying, together with the media's work in bringing the issue of polluted water to the forefront of political discourse, have prompted the government, private sector agencies, and community or-
\end{abstract}

ganizations to supply clean water to affected communities. A massive change in drinking water behaviors has occurred following the government's decision to supply reverse osmosis (RO) water to the affected communities. Informants perceived the provision of $\mathrm{RO}$ water as having brought about many positive outcomes in the health and disease progression of CKDu patients.

(C) 2021 The Author(s)

Published by S. Karger AG, Basel

\section{Introduction}

Environmental toxins and agrochemical pollutants are widely regarded as causative agents of CKD of unknown etiology $(\mathrm{CKDu})$ in Sri Lanka [1-4]. The belief that polluted water causes CKDu has been highlighted in the media and by political activists $[5,6]$. The high incidence of and death rate from CKDu from 1990 to 2018, especially in rice farmers in the age range of 35-55 years, and the spread of the disease into many newer locations have heightened public engagement with issues surrounding $\mathrm{CKDu}$. The new discourse around the disease defined it in biomedical terms as one caused by environmental toxins and agrochemical pollutants [6]. The public and me- 
dia outcry and the scientific community's findings prompted the government to take speedy action to resolve the issue of drinking water in $\mathrm{CKDu}$-endemic areas [7-11].

Following WHO research in 2008 [12], the Department of the Regional Director of Health in the North Central Province (NCP) instituted a range of actions in villages. These included the testing of blood and urine samples and the checking of water quality in dug wells and tube wells. Villagers were educated through local health education committees about the prevention of kidney disease, the avoidance of locally grown vegetables and fish, the use of safe drinking water, the safer use of pesticides, and the recognition of early symptoms and treatment of $\mathrm{CKDu}$ as provided by hospitals and clinics. Local health officers attached to the district secretariat (DS) divisions were instrumental in conducting the community education programs. Following a $45 \%$ increase in the number of CKDu patients from 10,921 in 2004 to 15,889 in 2009 [13], the government built 23 nephrology clinics in Anuradhapura district, and nephrologists were trained and appointed to hospitals and clinics in the affected areas. The government declared CKDu as an emergent disease requiring the intervention of the Ministry of Health, making CKDu a complete biomedical disease entity [6].

The classification of kidney disease (rajarata wakuga$d u$ lede) in farming communities in Anuradhapura district as a biomedical disease of national importance marked a new phase in CKDu research and management. The management of the disease became the responsibility of hospitals, clinics, and doctors, and CKDu patients were required to attend clinics regularly, get tested, follow the medical advice given, and make changes to their lifestyle and food patterns. The enormous funds allocated to research, community surveillance, the establishment of a National Renal Registry- a repository of individual patient data, and infrastructure development have given a hegemonic power to medical doctors over the management of the disease. Individual patients have become the passive objects of observation and research at hospitals, clinics, and laboratories [6].

The medical and epidemiological research and research on $\mathrm{CKDu}$ in the area led to the assumed link between the quality of drinking water and the disease being substantiated [6]. The research findings of epidemiologists and biomedical scientists, driven by lay ideas about a link between $\mathrm{CKDu}$ and contaminated drinking water with a foul taste, provided the basis for government action and a further research agenda. This new knowledge was corroborated through WHO research [12] that found drinking water and local foods in $\mathrm{CKDu}$-affected areas contain heavy metals. These findings were communicated to local communities through the media $[5,6]$

In this context, the present study examines how people explained their perception of polluted water as the cause of the disease and how the government responded to the public outcry by providing reverse osmosis ( $\mathrm{RO}$ ) water as an alternative to traditional drinking water sources. Then, the impact of new water use patterns and behaviors on the life and health of CKDu patients and their families is explained.

\section{Methods}

The study was conducted in 3 DS divisions in the NCP of Sri Lanka. The fieldwork was completed in 2013 and 2019. A random sample of 200 households was obtained in 2013 from 14 agricultural settlements in Medawachchiya and Kebithigollewa DS divisions in Anuradhapura district [5]. A second random sample of 200 households was selected in 2019 from 9 agricultural settlements in Medirigiriya DS division in Polonnaruwa district. The settlements were selected after consulting community leaders and staff in the respective DS offices. Health records of $30 \mathrm{CKDu}$ patients were used to analyze the progression of the disease. RO water use patterns were observed in 48 households. Data on RO plants and the prevalence of CKDu in the NCP were obtained from the National Renal Registry.

A team of 7 research assistants and the author conducted qualitative research, participant observation, and 100 open-ended, indepth interviews and 400 semi-structured interviews. The interviews were conducted with the chief householder or their spouse who gave their verbal consent. And, $15 \%$ of the households where interviews were carried out had CKDu patients. Through participant observation that included taking part in daily activities, household and farming tasks, and community meetings and discussions, the author examined how CKDu is experienced and perceived in 3 villages. The interviews were conducted in Sinhalese and translated into English.

The questionnaire data were computer entered and analyzed in SPSS version 24 and Microsoft Excel version 16.42. Textual data were translated into English, computerized, and analyzed in Atlas. ti program for textual data analysis.

\section{Results and Discussion}

The interviews with people in Medawachchiya in 2013 showed that they were concerned with the quality of water, which they thought was the main factor behind the disease. Data collected in 2013 showed a significant correlation between the use of dug wells and tube wells and the prevalence of CKDu (Fig. 1). de Silva 


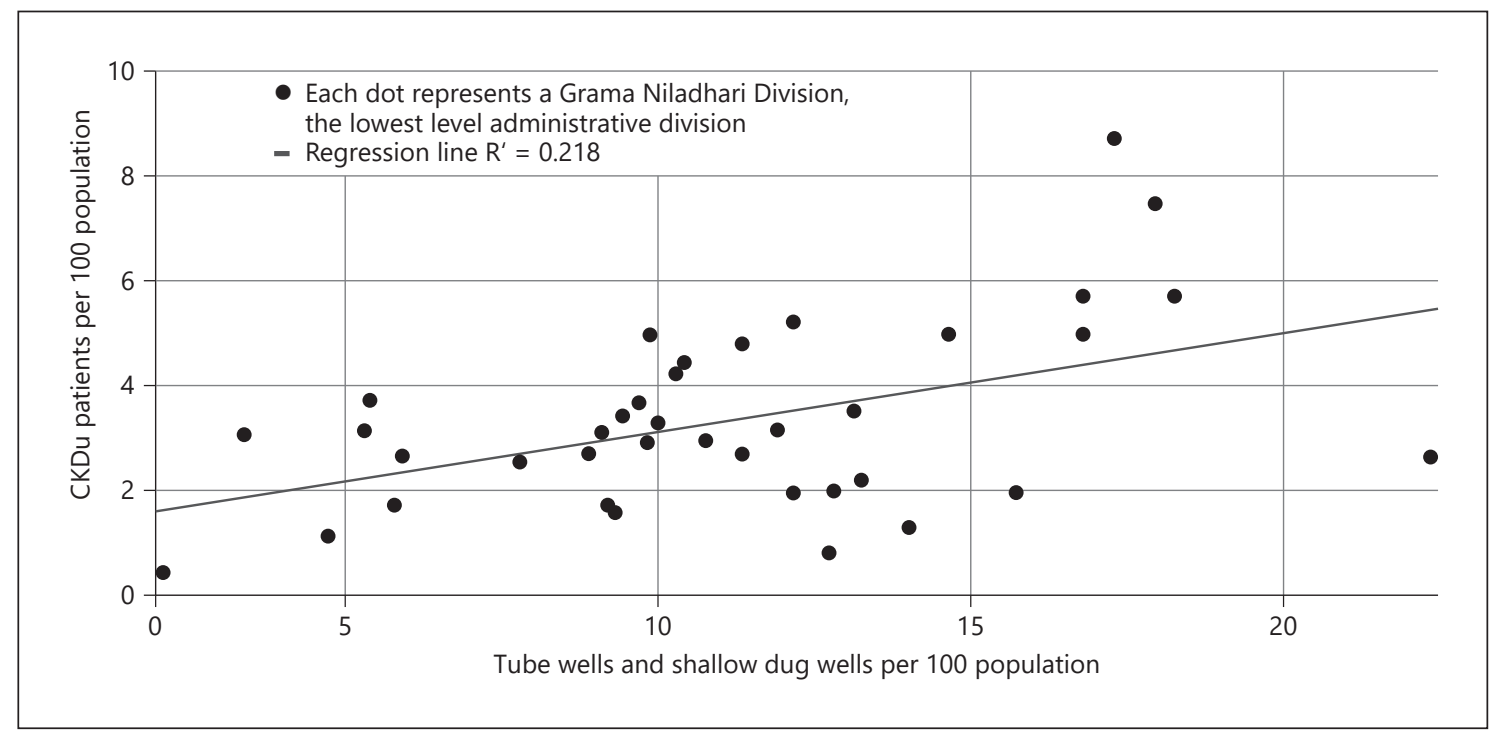

Fig. 1. Scatterplot of drinking water and CKDu patients in Medawachchiya DS division 2013. CKDu $=\mathrm{CKD}$ of unknown etiology; DS = district secretariat.

Water Sharing and Uses before the 1990s

The dry zone district of Anuradhapura has a history of over 2,500 years, during which local communities shared rainfed and irrigated water for the purposes of agriculture and drinking. Water stored in reservoirs or tanks was distributed through canals to rice-paddy fields through a system known as cascades [14]. The management of water for irrigation was a collaborative affair among the people in villages. Such collaborative water management in rice-paddy agriculture led to systems of labor sharing and labor exchange (attam), collective management of grassland, and joint management of fishing in reservoirs [15].

Dug wells formed the main source of drinking water in each homestead. Some households shared dug wells with other households for drinking purposes [5]. Water was considered pure and treated with the utmost respect, being used for religious purposes, such as the preparation of food for Buddhist monks (dana), and for the ritual of bathing the holy bodhi tree in Anuradhapura. The dug wells in homesteads were considered an asset, and, at the Sinhalese New Year, the first auspicious exchange ( $g a n$ udenu kiriima) of the household was performed by drawing a bucket full of water from the dug well and bringing it to the kitchen to prepare milk rice for the New Year meal. Well water was a symbol of prosperity, a medium of religious rituals and rites, and was offered to visitors as a gesture of goodwill.

Although dug wells were used for drinking and domestic purposes, when working in the rice-paddy fields, people used to drink water from the canals, which was considered clean and potable. People bathed and washed clothes in the village reservoir, which was also used for cattle bathing and fishing. The reservoirs were a source of edible vegetables such as underwater rhizome or lotus roots, water spinach, and various green leaves. The watersharing practices, with their underlying communal values, have come to an end following the realization that the water in dug wells, tube wells, canals, and reservoirs was polluted and making people sick with CKDu. Water from traditional sources in the area has now wholly metamorphosed into a symbol of disease and death.

\section{Commodification of Drinking Water}

People's understanding that polluted water was the cause of the disease was derived from experience. The smell, color, and texture of water, which left sediment in kettles when boiled and made holes in aluminum pots when stored, were taken as evidence for people's beliefs that drinking water was the cause of the disease. With the understanding that water is the cause of $\mathrm{CKDu}$, the traditional water use systems, based on the principles of collective property management, changed to a system of individualized management, particularly concerning drinking water. The new individualized systems of drinking water in Anuradhapura included the purchase of water bottles or water sold by liter in water shops, and the delivery of water to households on a monthly payment basis by private vendors in trucks. Rainwater harvesting at 


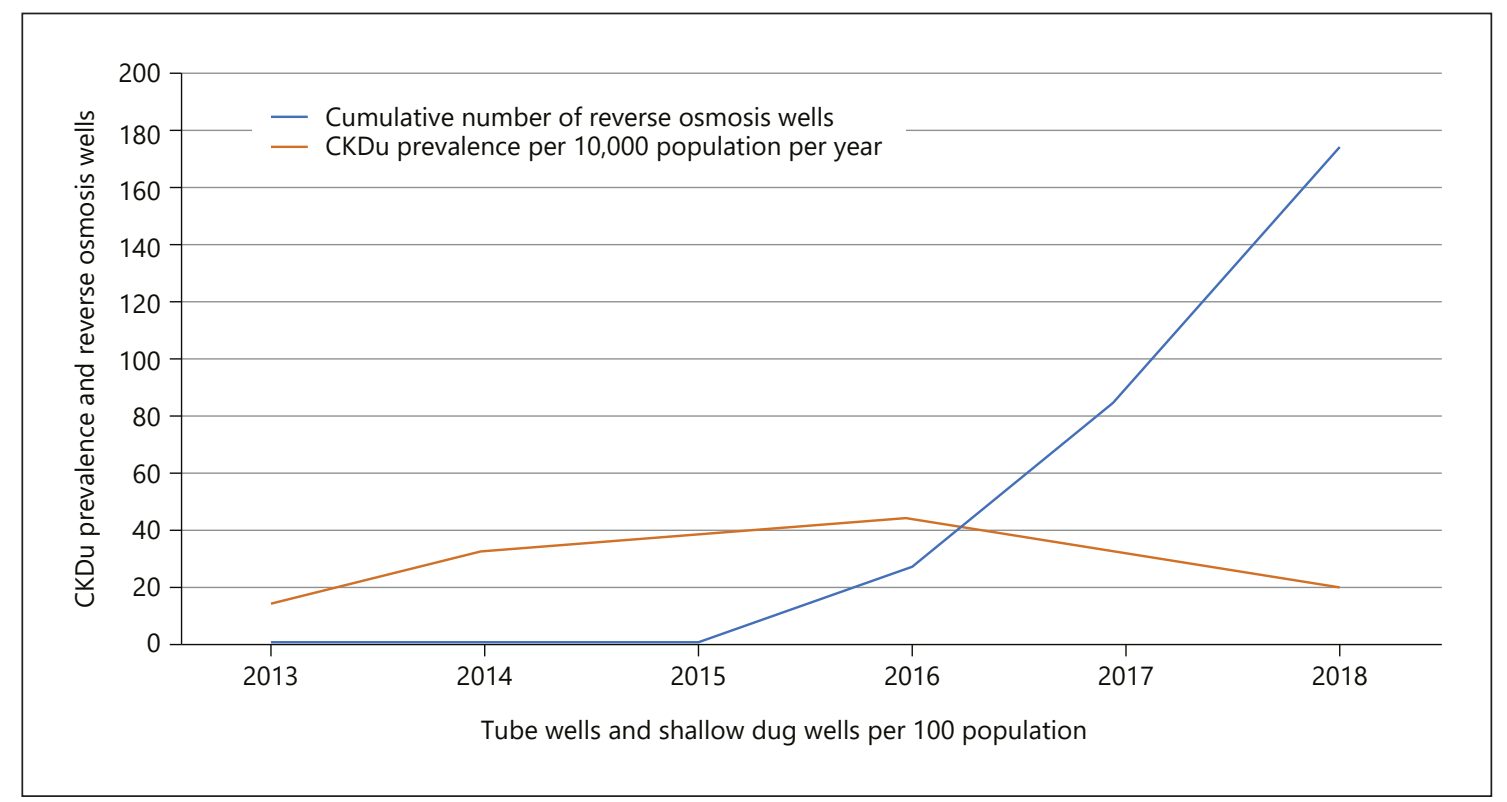

Fig. 2. Annual CKDu prevalence and cumulative number of RO well in NCP 2013-2018. Ro = reverse osmosis; $\mathrm{CKDu}=\mathrm{CKD}$ of unknown etiology; $\mathrm{NCP}=$ North Central Province.

home and fetching water from natural springs, mainly by the low-income families, are other individualized characteristics of obtaining drinking water. Drinking water has thus become a commodity requiring the expenditure of money and effort by individual families. The new water behaviors have led to the emergence of businesses in urban areas, where empty plastic containers are sold to needy households. Small boutiques in villages sell water by liter in plastic bottles and in big containers. Farmers now take water from home to the rice field and do not drink from the canals. Schoolchildren take a water bottle with them and do not drink from the school well or taps connected to the well. These practices show the manner in which water in Anuradhapura has become a commercialized property, which requires individual effort, money, and agency to obtain it for domestic use.

Epidemiological data showed that the prevalence of $\mathrm{CKDu}$ is less among people in the upper strata of the society who do not use dug wells for drinking $[6,16]$. These higher status families, which constitute $<10 \%$ of the population, mostly live by the main roads or in the urban area of communities, owning large rice-paddy acreage and rice mills. They have access to piped-in water and are free of the disease. The victims of the disease are the village rice-paddy laborers and those who provide labor for large landowners while working on their small plots of ricepaddy. They are often socially discriminated against through the use of derogatory terms such as wakugadu leddu (people suffering from $\mathrm{CKDu}$ ), alcoholics, gamblers, outsiders, and colonists. CKDu is thus seen as a disease of the poor "agricultural settlers" who depend on the land and rice cultivation for their livelihoods [16].

\section{Provision of RO Water and Changed Scenario}

The study in 2019 in Medirigiriya DS division in Polonnaruwa district [17] and other recent research [18] indicate a change in the CKDu profile in Sri Lanka after the introduction of $\mathrm{RO}$ water. There was a significant correlation (Fig. 2) between the number of RO wells and CKDu prevalence in the NCP.

The provision of $\mathrm{RO}$ water as the recommended source of drinking water in the NCP is part of a larger program of rural water supply undertaken by the government with financial support from the World Bank. The first RO water program started in 2010 with an allocation of rupees (Rs.) 900 million by the Sri Lanka Treasury to purchase RO machines for the areas worst affected by $\mathrm{CKDu}$ [19], and the large-scale supply of RO plants in the NCP began after 2014. The World Bank supported the RO program with the understanding that "the beneficiaries from the areas most affected by $\mathrm{CKDu}$ were convinced that early symptoms had been brought under control by drinking reverse-osmosis-purified water" [20]. The rural water supply program of RO water wells
40

Ann Nutr Metab 2020;76(suppl 1):37-42 DOI: $10.1159 / 000515018$ de Silva 
gradually replaced the traditional drinking water sources that had been used by villagers for centuries. The establishment of RO water plants in the NCP was considered an interim measure to combat the environmental toxins and agrochemical pollution of drinking water and to provide clean and readily available sources of drinking water for villagers until comprehensive water supply programs were introduced.

The change from private dug wells to $\mathrm{RO}$ wells has had many consequences for the families and households. As each RO plant is situated centrally in its locality, many people must travel a distance to fetch water in heavy plastic containers. Some private vendors run trucks on the village roads several times a day supplying $\mathrm{RO}$ water to households for Rs. 1.50-3.00 per L. Most families use plastic containers with a capacity of 30-40 L to collect RO water from the plants and spend about Rs. 45 (approximately USD 0.25). Many people told us that because they buy the water, they use it with more care and do not waste it.

People in the villages said many good things about RO water. A CKDu patient in Medirigiriya stated that "before I started on RO water, I had feelings of vomiting and nausea. Often, I felt tired and could not carry out even a simple task like sweeping the compound. Now I feel much better. I can work in our vegetable patch. Now I cultivate onions, and every day I take care of my vegetable garden." Many patients in Medirigiriya told us that symptoms such as back pain, headache, and burning sensations when urinating disappeared after they started drinking RO water. The quality of life in these patients has thus improved since they started using $\mathrm{RO}$ water.

\section{Health Effects of RO Drinking Water}

Health records from $30 \mathrm{CKD}$ patients in Medirigiriya who volunteered to share them revealed a significant improvement in kidney function after starting on $\mathrm{RO}$ water as revealed in decreased serum $\mathrm{Cr}$ (SCr) values. A paired samples $t$ test was conducted to compare the $\mathrm{SCr}$ values at time 1 (when the disease was first diagnosed at the hospital) and time 2 (the last time the patient visited the hospital). There was a significant difference between the scores for time $1(\mathrm{M}=2.97, \mathrm{SD}=2.08)$ and time $2(\mathrm{M}=$ $2.19, \mathrm{SD}=1.49), t(2.9)=4.7, p<0.0001$. These results suggest that the switch to $\mathrm{RO}$ water consumption and other behavioral changes, such as drinking 3-4 L of clean (RO) water a day per person, refraining from smoking and alcohol use, and avoiding long hours of work under the hot sun, adopted by patients and their families may have improved the SCr values of CKDu patients.

Drinking Water and Kidney Health in Sri Lanka

\section{Conclusion}

Our study shows that changing over to RO water has had positive health outcomes and has reduced the progression of CKDu. The identification of polluted drinking water as a cause of CKDu has had implications for the local hydraulic culture that was previously based on the sharing and management of water by local communities for the purposes of irrigated rice agriculture, domestic use, and ritual practices. Drinking water becoming a commodity and the need for individual action to fetch it are other outcomes of this new development. Our study also shows that interventions addressing the environmental contamination of water at the point of use or household level can be considered an essential interim measure until such time as reliable, safe piped-in water connections are available for each household in the villages.

\section{Acknowledgments}

I gratefully thank Dr. Prasannajit de Silva for valuable comments on the manuscript and professor Steven Albert for data analysis support.

\section{Statement of Ethics}

Participants gave their verbal consent, and interviews were conducted in Sinhalese. Ethical approval was obtained from the Ethical Review Committee, Faculty of Medicine, University of Peradeniya.

\section{Conflict of Interest Statement}

M.M.A.S. received travel expenses and registration fees from Danone Research to attend the 2018 and 2019 Hydration for Health Scientific Conference.

\section{Funding Sources}

This research was supported by ISN-H4KH Initiative with a grant from Danone Nutricia Research.

Ann Nutr Metab 2020;76(suppl 1):37-42 DOI: $10.1159 / 000515018$ 


\section{References}

1 Bandara JM, Wijewardena HV, Liyanege J, Upul MA, Bandara JM. Chronic renal failure in Sri Lanka caused by elevated dietary cadmium: Trojan horse of the green revolution. Toxicol Lett. 2010 Sep 15;198(1):33-9.

2 Edirisinghe EANV, Manthrithilake $\mathrm{H}$, Pitawala HMTGA, Dharmagunawardhane HA, Wijayawardane RL. Geochemical and isotopic evidences from groundwater and surface water for understanding of natural contamination in chronic kidney disease of unknown etiology (CKDu) endemic zones in Sri Lanka. Isotopes Environ Health Stud. 2018 May 4;54(3):244-61.

3 Rango T, Jeuland M, Manthrithilake H, McCornick P. Nephrotoxic contaminants in drinking water and urine, and chronic kidney disease in rural Sri Lanka. Sci Total Environ. 2015 Jun 15;518-9:574-85.

4 Levine KE, Redmon JH, Elledge MF, Wanigasuriya KP, Smith K, Munoz B, et al. Quest to identify geochemical risk factors associated with chronic kidney disease of unknown etiology $(\mathrm{CKDu})$ in an endemic region of Sri Lanka: a multimedia laboratory analysis of biological, food, and environmental samples. Environ Monit Assess. 2016 Oct 1;188(10): 548.

5 de Silva MWA. Drinking water and chronic kidney disease of unknown aetiology in Anuradhapura, Sri Lanka. Anthropol Med. 2019 Sep 2;26(3):311-27.
6 de Silva MWA. Bio-media citizenship and chronic kidney disease of unknown etiology in Sri Lanka. Med Anthropol. 2018 Apr 3; 37(3):221-35

7 Gunawardena N. Science and politics of mass kidney failure in Sri Lanka. 2012. Available online: https://groundviews.org/2012/08/19/ science-and-politics-of-mass-kidney-failurein-sri-lanka/.

8 Kannangara N. Pesticides registrar, agriculture department, under fire. The Sunday Leader Newspaper. 2014 Aug 3.

9 Bandara H. FAO blamed for the spread of chronic kidney disease. Sunday Times. 2012 Oct 21.

10 Chavkin S, Jester AB. Mystery in the field. The center for public integrity. 2012. Available at: https: //cloudfront-files-1.publicintegrity.org/ documents/pdfs/MysteryintheFields.pdf.

11 Wijewardena DA. President praised for taking bold step to ban glyphosate. Scientists recommend organic agriculture as alternative to agrochemical-based farming. The Island Newspaper. 2015 May 24.

12 Jayatilake N, Mendis S, Maheepala P, Mehta FR. Chronic kidney disease of uncertain aetiology: prevalence and causative factors in a developing country. BMC Nephrol. 2013 Dec $1 ; 14(1): 180$

13 Annual health bulletin. 2010.

14 Panabokke CR. Small village tank system of Sri Lanka: their evolution, setting, distribu- tion and essential functions. Colombo, Sri Lanka: Hector Kobbekaduwa Agrarian Research and Training Institute; 2009.

15 Leach ER. Pul Eliya: a village in Ceylon. Cambridge, England: Cambridge University Press; 1961 Jan 2.

16 de Silva MWA, Albert SM, Jayasekara JM, Jayasekara JM. Structural violence and chronic kidney disease of unknown etiology in Sri Lanka. Soc Sci Med. 2017 Apr 1;178:184-95.

17 de Silva MWA, Albert SM. Initial evidence for the benefits of purified and reverse osmosis water in reducing chronic kidney disease of unknown etiology in Sri Lanka. (unpublished data).

18 Ranasinghe AV, Kumara GWGP, Karunarathna RH, De Silva AP, Sachintani KGD, Gunawardena JMCN, et al. The incidence, prevalence and trends of chronic kidney disease and chronic kidney disease of uncertain aetiology $(\mathrm{CKDu})$ in the North Central Province of Sri Lanka: an analysis of 30,566 patients. BMC Nephrol. 2019 Dec 1;20(1):338.

19 Jeya Raj R. Is reverse osmosis (RO) treatment the answer to solving the CKDu riddle? Available from: http://www.iwmi.cgiar.org/2014/ $10 /$ reverse-osmosis-ro-treatment-answersolving-ckdu-riddle/2014.

20 World Bank Report 2017 No: PAD1223:3, page 34. Available from: http://documents.worldbank.org/curated/en/615581499954244065/ pdf/115781-PPAR-P058067-PUBLIC.pdf. 